\title{
Spatial variability and temporal trends of precipitation over the Loess Plateau of China: 1957-2013
}

\author{
Yu Yang ${ }^{1.2}$, Yin Zhe ${ }^{1.2}$, Shan Zhijie ${ }^{1.2}$, Qin Wei ${ }^{1.2}$, Li Bai ${ }^{1.2}$, Guo Qiankun ${ }^{1.2}$, Long Wei ${ }^{3}$, Wang Qun ${ }^{4}$, Zhang Jingfeng ${ }^{1.2}$ \\ ${ }^{1}$ State Key Laboratory of Simulation and Regulation of Water Cycle in River Basins, China Institute of Water Resource and \\ Hydropower Research, Beijing, China \\ ${ }^{2}$ Research Center of Soil and Water Conservation of the Ministry of Water Resources, Beijing, China \\ ${ }^{3}$ Hunan Prospecting Designing and Research General Institute for Forestry, Hunan, China \\ ${ }^{4}$ Haihe Basin Soil and Water Conservation Center, Haihe River Water Conservancy Commission, MWR, Tianjin, China
}

\begin{abstract}
Accurate information about regional precipitation and trends in spatiotemporal variation is crucial, both from the perspective of quantifying water budgets and to determine appropriate vegetation restoration. The objectives of this study were to evaluate spatiotemporal changes in precipitation and to analyze the monthly, annual, and seasonal precipitation trends of 85 stations in the Loess Plateau during 1957-2013. The Mann-Kendall test and Sen's slope estimator were applied to analyze the precipitation data. Monthly precipitation trends exhibited apparent regional differences over the Loess Plateau, significant increasing trends in rainfall were found in winter. On the seasonal scale, the magnitude of significant negative trends in seasonal rainfall varied from $0.595 \mathrm{~mm} / \mathrm{yr}^{2}$ to $2.732 \mathrm{~mm} / \mathrm{yr}^{2}$. The magnitude of significant positive trends varied from $0.010 \mathrm{~mm} / \mathrm{yr}^{2}$ to $1.987 \mathrm{~mm} / \mathrm{yr}^{2}$. One of the most remarkable findings was that all the stations showed significant positive trends in winter. For annual average rainfall, the magnitude of significant positive trends varied from $2.075 \mathrm{~mm} / \mathrm{yr}^{2}$ to $3.427 \mathrm{~mm} / \mathrm{yr}^{2}$. No significant negative trends were detected. Although, the annual average rainfall over the Loess Plateau showed a non-significant increasing trend, the seasonal and regional pattern was obvious. Such findings can provide important implications for ecological restoration and farming operations across the study region.
\end{abstract}

\section{Introduction}

Land degradation research is mainly focused on the biota (mainly plants) and the soil changes due to the human activities. Precipitation is a fundamental component of the hydrological cycle, and it is also a major limiting element in arid and semi-arid ecosystems [e.g. 1-3]. Precipitation has long been recognized as a crucial water resource, and it is the most important factor linking edaphic and biotic environments [4]. Ecosystems present varying degrees of dependency on precipitation. Recently, changes in precipitation patterns and gradients have accelerated in terms of the frequency, magnitude, and spatial scale of precipitation events. These changes have the potential to alter hydrological cycles, energy balances, and biogeochemical processes, particularly in the semi-arid and arid ecosystems, owing to the combination of water stress and land degradation in these regions [5].

Changes in precipitation patterns may lead to droughts and floods, thus affecting vegetation restoration efforts, food security, and potentially even the quality of life and production capacities in local economies. Consequently, characterizing the spatial and temporal variability of precipitation with time series data is important for ensuring ecosystem sustainability. More recently, much attention has been paid to the variability of precipitation with the goals of understanding the dynamics of water availability and predicting water supply variations that may result from possible future climate changes. To date, many studies have conducted analyses of precipitation variability at the global level, and regional studies have been conducted in Africa, North America, several European countries, Iran, India, and China [e.g. 6-10].. Moreover, the spatial variability in precipitation also has been investigated in different sub-regions, including the Beijiang River basin, Yellow River basin, Lancang River basin, North China Plain, and other northwestern parts of China [e.g. 11-15]. Previous studies have revealed long-term variation characteristics and changing trends in annual precipitation. However, detailed information is still limited regarding the spatial and temporal variability of precipitation over large-scale areas in typical arid and semi-arid inland ecosystems.

The Loess Plateau region has deep loess soils and suffers from severe erosion. Owing to the uneven regime of available water resources and intensive human disturbances, ecosystems in this region are seasonally or episodically under water stress and vulnerable to even slight increases in the water deficit, which indicates that this region may be quite sensitive to climate variations. It is thus crucial to determine how rainfall varied over the past decades. Due to the vulnerability of the water-

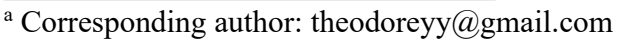


limited ecosystems to climate change, lands require careful management to realize optimum ecosystem services [16]. Management efforts aimed at selecting suitable vegetation patterns to achieve the long-term sustainability of ecosystem restoration projects are sorely needed. Human land use has greatly changed in the Loess Plateau since the development of the "Grain for Green" project in 1999. However, vegetation restoration and water soil conservation strongly depend on variations in precipitation. Therefore, investigations of the spatial and temporal variability of precipitation over this region are required urgently.

With these issues in mind, the present study aimed to address three major questions. First, has there been an increasing trend in precipitation over the Loess Plateau during the most recent six decades? Second, were there any changes in seasonal precipitation variation over the Loess Plateau and, if so, which season exhibited the strongest rainfall changes? To address both questions, long-term trends in the annual, seasonal, and monthly mean rainfall were investigated for 85 stations in the Loess Plateau for the period 1957-2013. The magnitude of a trend was measured by assuming that it was a linear phenomenon. The statistical significance of a trend at a particular site was assessed by the Mann-Kendall test with considerations of serial correlation. Specifically, the effective sample size method was applied to eliminate the effect of serial correlation on the Mann-Kendall test results.

\section{Methods}

\subsection{Study area}

The Loess Plateau is one of the four major plateaus in China, which is situated in the upper and middle reaches of the Yellow River. The plateau extends from $33^{\circ} 43^{\prime}$ to $41^{\circ} 16^{\prime} \mathrm{N}$ and from $100^{\circ} 54^{\prime}$ to $114^{\circ} 33^{\prime} \mathrm{E}$ and is surrounded by Taihang, Riyue-Helan, Qingling, and Yinshan Mountains. The total area of the plateau is greater than $600,000 \mathrm{~km}^{2}$, with an unique climatological characteristics (such as a large daily range in temperature, uneven temperature distribution, large variations in rainfall, and high-intensity storms) and physiographic characteristics. The plateau has the nearly most severe soil and water loss rates in the world, and more than $60 \%$ of the land suffers from soil erosion. In order to improve local environments and prevent soil and water loss, the "Grain for Green" project was started by the central government in 1999. Because of water restrictions, plants initially grew well but degraded over time. Looming water shortages thus may represent an important constraint for future vegetation restoration efforts, further illustrating the urgent requirement for describing trends and long-term variability of precipitation in this region.

\subsection{Data collection}

Rainfall data of 85 stations operated by the meteorological organization of China were used to evaluate the rainfall variability throughout the Loess Plateau. These stations were selected because they have rainfall records spanning at least 57 years and are spread relatively uniformly throughout the Loess Plateau. The data set included daily rainfall data from 1957 to 2013 . This period is the maximum common time period of rainfall data recorded at all 85 stations. All the stations belong to the National Standard Station and National Principle Station programs. The annual rainfall, monthly rainfall, and the number of rainy days per year were calculated from daily rainfall data. The number of rainy days per year was defined as the number of days of the year with a rainfall amount greater than $1 \mathrm{~mm}$ [17]. Meanwhile, the RclimDex procedure was applied to execute the quality controls. Stations with missing observations for more than 3 consecutive days were excluded [18]. No seasonal value was determined if one month's data was missed.

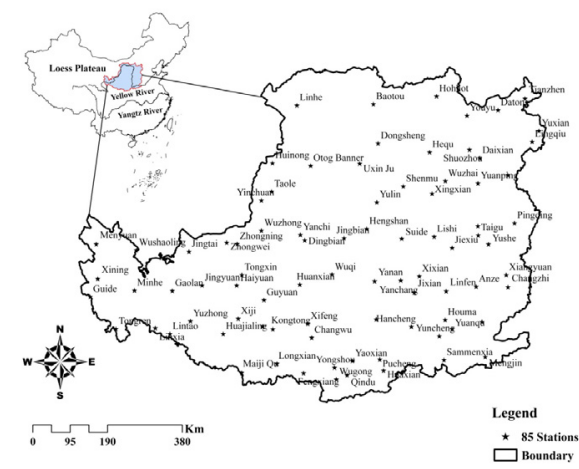

Figure 1. Distribution of the 85 meteorological stations in the Loess Plateau of China.

\subsection{Statistical tests for trend analysis}

The Mann-Kendall test and Sen's slope estimator were applied to the precipitation data to detect trends. The Mann-Kendall test was applied to identify tendencies in rainfall variation for each station. Sen's slope method was used to calculate the amplitude of variation. The ArcGIS 9.3 software was used to map the spatial distribution of stations with significant changes at the significance level $\alpha<0.01$ and $\alpha<0.05$.

The Mann-Kendall test is a non-parametric test that can be used to detect the presence of a monotonic increasing or decreasing trend within a time series in the absence of any seasonal variation or other cycles [e.g. 19-21]. The Mann-Kendall test does not require the data to be distributed normally. Additionally, it has a low sensitivity to abrupt breaks due to inhomogeneous time series [22]. Consequently, the Mann-Kendall test has been widely used to test for randomness and trends in climatology research. Depending on the test, the null hypothesis $\mathrm{H}_{0}$ states that the time series $\left(\mathrm{x}_{1}, \mathrm{x}_{2}, \ldots, \mathrm{x}_{\mathrm{n}}\right)$ includes $\mathrm{n}$ dependent and identically distributed random samples. The alternative hypothesis $\mathrm{H} 1$ of a two-sided test is that the distributions of $\mathrm{x}_{\mathrm{k}}$ and $\mathrm{x}_{\mathrm{j}}$ are not identical for all $k, j \leq n$ with $k \neq j$; in other words, this indicates that there are upward or downward trends in the 
sequence. The test statistic $S$ was built when the time series had 10 or more values. The test statistic $S$, which has a mean value of zero, was computed based on Equations (1) and (2) as follows:

$$
S=\sum_{k=1}^{n-1} \sum_{j=k+1}^{n} \operatorname{Sgn}\left(x_{j}-x_{k}\right)
$$

$$
\operatorname{Sgn}\left(x_{j}-x_{k}\right)= \begin{cases}1 & \text { if }\left(x_{j}-x_{k}\right)>0 \\ 0 & \text { if }\left(x_{j}-x_{k}\right)=0 \\ -1 & \text { if }\left(x_{j}-x_{k}\right)<0\end{cases}
$$

where $\mathrm{x}_{\mathrm{j}}$ and $\mathrm{x}_{\mathrm{k}}$ represent the observations in years $j$ and $k$, respectively. When the time series contained less than 10 values, the $S$ test was used. If $S<0$, a decreasing trend was assumed; otherwise, an increasing trend was assumed. The variance was computed as

$$
\operatorname{Var}(S)=\frac{\left[n(n-1)(2 n+5)-\sum_{i=1}^{m} t_{(t}\left(t_{i}-1\right)\left(2 t_{i}+5\right)\right]}{18}
$$

In Equation (3), $n$ is the number of data points, $m$ is the number of tied groups, and ti is the number of data points in the ith group. In our study, there were more than 10 samples; therefore, the standard normal variable $Z$ was computed using Equation (4):

$$
Z=\left\{\begin{array}{ccc}
\frac{S-1}{\sqrt{\operatorname{Var}(S)}} & \text { if } & S>0 \\
0 & \text { if } & S=0 \\
\frac{S+1}{\sqrt{\operatorname{Var}(S)}} & \text { if } & S<0
\end{array}\right.
$$

Positive values of $Z$ indicate an increasing trend and negative values indicate a decreasing trend. If the absolute value of the test statistic $Z$ is greater than $Z_{1-\alpha / 2}$ at the $\alpha$ significance level, the null hypothesis is rejected and the observations are considered to display a significant monotonic increase or decrease. Otherwise, the alternative hypothesis is rejected and the observations are considered to be randomly ordered with no trends.

Sen's method is often combined with the Mann-Kendall test in many studies to explore trends and amplitudes of variation. It is a consistent non-parametric estimator for the coefficient of a linear regression. If a linear trend is present in a time series, then the true slope of the trend can be estimated by Sen's slope estimator. The slope estimates of $\mathrm{N}$ pairs of data are computed as

\begin{tabular}{|c|c|c|c|c|c|c|c|}
\hline \multirow{2}{*}{ Month } & \multirow{2}{*}{$\begin{array}{c}\text { Number of } \\
\text { stations with } \\
\text { significant } \\
\text { changing trend }\end{array}$} & \multicolumn{3}{|c|}{$\begin{array}{c}\text { Number of stations with } \\
\text { increasing trend }\end{array}$} & \multicolumn{3}{|c|}{$\begin{array}{c}\text { Number of stations with } \\
\text { decreasing trend }\end{array}$} \\
\hline & & * & $* *$ & Total & $*$ & $* *$ & Total \\
\hline January & 81 & 3 & 78 & 81 & 0 & 0 & 0 \\
\hline February & 79 & 6 & 73 & 79 & 0 & 0 & 0 \\
\hline March & 52 & 9 & 43 & 52 & 0 & 0 & 0 \\
\hline April & 21 & 4 & 4 & 8 & 10 & 3 & 13 \\
\hline May & 8 & 5 & 3 & 8 & 0 & 0 & 0 \\
\hline June & 4 & 1 & 3 & 4 & 0 & 0 & 0 \\
\hline July & 5 & 0 & 0 & 0 & 3 & 2 & 5 \\
\hline August & 8 & 0 & 0 & 0 & 7 & 1 & 8 \\
\hline
\end{tabular}
$Q_{i}=\frac{x_{j}-x_{k}}{j-k}$ for $\mathrm{i}=1,2,3, \ldots, \mathrm{N}$

Table 1. Mann-Kendall test results for the changing trends at two significance levels of monthly precipitation for 85 meteorological stations. respectively, and $Q_{i}$ is the Sen's slope estimator. If the sequence length of data is $N$, the slope can be estimated with Equation (6):

$Q_{\text {med }}= \begin{cases}Q_{(N+1) / 2]} & \text { if } N \text { is odd } \\ \frac{1}{2}\left[Q_{N / 2}+Q_{(N+2) / 2]}\right. & \text { if } N \text { is even }\end{cases}$

The $Q_{m e d}$ value is typically tested with a two-tailed normal distribution at the $100(1-\alpha) \%$ confidence level, and the true slope can be obtained by the non-parametric test. In the present study, two different confidence levels were calculated using Equation (7):

$C_{\alpha}=Z_{1-\alpha / 2} \sqrt{\operatorname{Var}(S)}$

where $\operatorname{Var}(\mathrm{S})$ was calculated as in Equation (3) and $\mathrm{Z}_{1-\alpha / 2}$ was obtained by the standard normal distribution. Two values, $\mathrm{M}_{1}=(\mathrm{N}-\mathrm{C} \alpha) / 2$ and $\mathrm{M}_{2}=(\mathrm{N}+\mathrm{C} \alpha) / 2$, were explored. $Q_{\min }$ and $Q_{\max }$ are the $\mathrm{M}_{1}$ th largest and the $\left(\mathrm{M}_{2}+1\right)$ th largest of the $N$ ordered slope estimates $Q_{i}$ under the lower and upper limits of the confidence interval. If $M_{l}$ is not a whole number, the lower limit is interpolated. Meanwhile, if $M_{2}$ is not a whole number, the upper limit is interpolated.

\section{Results and Discussion}

\subsection{Monthly trends}

The Mann-Kendall test was applied to detect monthly precipitation trends for all the stations. The results clearly showed that some stations had statistically significant trends at the $1 \%$ and $5 \%$ significance levels (Table 1). The monthly precipitation presented both increasing and decreasing trends depending on the station location. The precipitation in July and August showed a decreasing trend for four or five stations. Moreover, we observed that most stations had a significant increasing trend during the winter months, and mixed trends were identified in April. However, no significant trends were found in September for most stations in the Loess Plateau. Consequently, the monthly precipitation showed changing trends that were spatially and temporally variable. 


\begin{tabular}{cccccccc} 
September & 2 & 1 & 1 & 2 & 0 & 0 & 0 \\
October & 5 & 1 & 4 & 5 & 0 & 0 & 0 \\
November & 29 & 5 & 24 & 29 & 0 & 0 & 0 \\
December & 63 & 14 & 49 & 63 & 0 & 0 & 0 \\
\hline
\end{tabular}

${ }^{*}$ Trends statistically significant at the $95 \%$ confidence level

${ }^{* *}$ Trends statically significant at the $99 \%$ confidence leve

Specifically, in January and February, markedly increasing trends were detected at 81 and 79 stations, respectively, and these trends were significant at the $\alpha<$ 0.05 significance level. Moreover, these stations were rather evenly distributed throughout the whole region. In March, 52 stations had a positive trend $(\alpha<0.05)$, whereas the other stations showed no significant trends. In April, a significant decreasing trend was found for 13 stations, which were mainly distributed in the south. Meanwhile, a significant increasing trend was detected for eight stations that were scattered in the eastern and western parts of the plateau. In May and June, eight and four stations showed an increasing trend, respectively. In contrast, in July and August, a remarkable decreasing trend was found at five and eight stations, respectively, and these were distributed randomly over the Loess Plateau. In September, the Wutai Mountain station in the east and the Wushaoling station in the west showed a significant increasing trend. Then, the increasing trend became more pronounced for both of these stations in October. In November, 29 stations, which were concentrated in the west and scattered in the northeast, showed significant positive trends. In December, a notable increasing trend was found for 63 stations, and these stations were distributed rather evenly throughout the Loess Plateau.

Monthly precipitation trends exhibited apparent regional differences over the Loess Plateau. In the northeastern part, most stations had an increasing trend in January, February, and December, whereas they had a decreasing trend in August, similar to some of the stations that were distributed in the northwest. In the western part, most stations had an increasing trend in January, February, March, November, and December. However, in the southern part, a significant decreasing trend in monthly rainfall was found mainly in April. In the middle part, most stations exhibited significant mixed trends in January, February, and December.

\subsection{Seasonal trends}

According to the results from statistical tests, significant positive trends were found at 11 stations in the spring, and nearly $70 \%$ of the stations showed increasing trends during this time. Significant negative trends ranged between (-) $0.595 \mathrm{~mm} / \mathrm{yr}^{2}$ at the Qindu station and (-) $0.746 \mathrm{~mm} / \mathrm{yr}^{2}$ at the Wugong station during the spring season. The lowest and highest significant increases in precipitation during the spring were detected over Yuxian and Menyuan, respectively, and the increases amounted to (+) $0.541 \mathrm{~mm} / \mathrm{yr}^{2}$ at Yuxian and (+) 1.987 $\mathrm{mm} / \mathrm{yr}^{2}$ at Menyuan. The majority of the trends for summer precipitation were negative, which is an adverse outcome in this region, and such trends were found at approximately $77 \%$ of the stations. However, significant decreasing trends were only detected at two stations during the summer. The lowest and highest significant decreases in precipitation during the summer were detected over the Linqiu station and the Wutai Mountain station, respectively, and the decreases amounted to (-) $1.446 \mathrm{~mm} / \mathrm{yr}^{2}$ at Linqiu and (-) $2.732 \mathrm{~mm} / \mathrm{yr}^{2}$ at Wutai Mountain. Meanwhile, 19 stations exhibited positive trends, but only one station (Qindu) exhibited significant increasing trends; the precipitation at Qindu increased at a rate of (+) $1.092 \mathrm{~mm} / \mathrm{yr}^{2}$. Furthermore, similar to the spring series, 48 stations exhibited positive trends in the autumn, and significant positive trends were detected at six stations. The lowest and highest significant increases in precipitation during the autumn were detected over the Xining and Wutai Mountain stations, respectively, and the increases amounted to $(+) 0.533 \mathrm{~mm} / \mathrm{yr}^{2}$ at Xining and $(+) 1.807 \mathrm{~mm} / \mathrm{yr}^{2}$ at Wutai Mountain. No significant decreasing trends in precipitation were found with the trend test in autumn. In the winter, all of the stations showed significant increasing trends, and the increases ranged from $(+) 0.010 \mathrm{~mm} / \mathrm{yr}^{2}$ at Guide station to (+) $0.473 \mathrm{~mm} / \mathrm{yr}^{2}$ at Yuanqu station.

Overall, seasonal precipitation trends exhibited obvious seasonal and regional patterns over the Loess Plateau during the past several decades (Figure 2). For instance, precipitation generally exhibited increasing trends in the winter but decreasing trends in the summer, which is the rainy season, and the changing trends in the eastern and northern parts of the plateau were more apparent than those in the southern and middle parts. Hence, these results indicate that there has been a seasonal movement toward concentrated precipitation in the winter season. The rainfall trends in summer over the Loess Plateau support the results of $\mathrm{Lu}$ [23], which identified that the rainfall in summer decreased across this region during the past few decades. It also revealed that such changes in summer rainfall possibly resulted from the changes in the East Asian summer monsoon system.

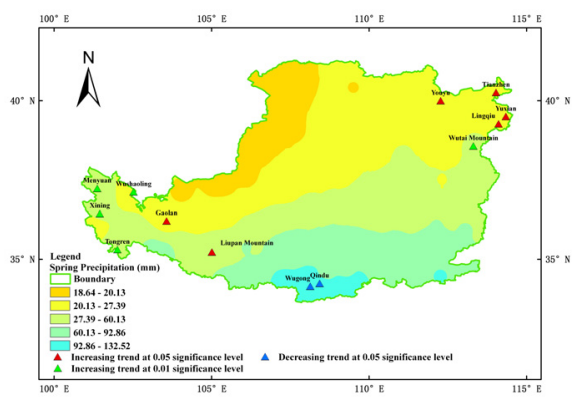



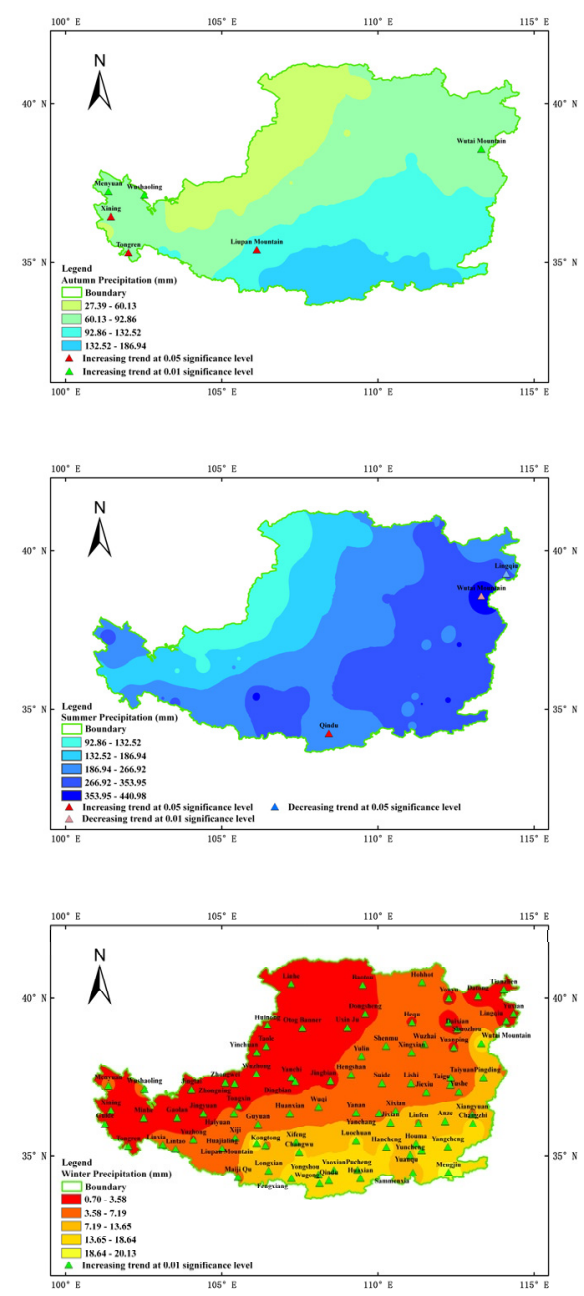

Figure 2. Spatial distribution of seasonal precipitation on the Loess Plateau (1957-2013)

\subsection{Annual trends}

Most of the trends in annual precipitation were insignificant at the $95 \%$ and $99 \%$ confidence levels. Only three stations showed striking increasing trends, and these stations were located in the high cold western area of the Loess Plateau, Menyuan, Wushaoling, and Xining (Figure 3). Furthermore, all of the remarkable trends were expressed as increases in magnitude: the annual precipitation change varied between 2.075 $\mathrm{mm} / \mathrm{yr}^{2}$ at the Xining station and $3.427 \mathrm{~mm} / \mathrm{yr}^{2}$ at the Wushaoling station. The distribution of the annual precipitation trends showed that the increasing trends mostly occurred in the northwestern part of the Loess Plateau. In contrast, no significant trends were detected in the eastern, southern, and middle parts of the plateau. While the trends were insignificant, most stations that were situated in the southeastern part of the Loess Plateau displayed a tendency toward increasing trends, whereas the stations scattered in the middle and southern parts displayed a tendency toward decreasing trends. As a whole, the annual average precipitation over this region showed a non-significant increasing trend $(p>0.05$, $\left.Q=0.37 \mathrm{~mm} / \mathrm{yr}^{2}\right)$.

Fan et al. (2012) explored the temporal variation in the monthly, seasonal, and annual rainfall over the North
China Plain from 1960 to 2007, the result revealed a significant increasing trend in precipitation during winter months for most parts of the plain [14]. Meanwhile, no significant trend was detected for the annual rainfall in most parts of that region, which was consistent with this study. However, for the annual average precipitation, Xin et al. (2008) identified a significant decreasing trend from 1958-2008 $\left(p<0.05, \mathrm{Q}=-1.40 \mathrm{~mm} / \mathrm{yr}^{2}\right)$, basing on the 60 stations within and 27 stations adjacent to the Loess Plateau [24]. Likewise, when choosing the annual average precipitation from 1958 to 2008 in our study, the result investigated an insignificant decreasing trend $\left(p>0.05, \mathrm{Q}=-0.20 \mathrm{~mm} / \mathrm{yr}^{2}\right)$, inconsistent with Xin's study. This was possibly attributed to the distribution of the meteorological stations, and not involved the effect sample size method on the Mann-Kendall test in Xin's study. In addition, Wang et al. (2012) reported a nonsignificant decreasing trend $\left(p>0.05, \mathrm{Q}=-0.58 \mathrm{~mm} / \mathrm{yr}^{2}\right)$ for the Loess Plateau from 1961 to 2010 [25]. In the present study, although the annual average precipitation exhibited a non-significant increasing trend from 1957 to 2013, while from 1961 to 2010 a non-significant decreasing trend was detected $\left(p>0.05, \mathrm{Q}=-0.04 \mathrm{~mm} / \mathrm{yr}^{2}\right)$, which approved the conclusion of Wang et al. (2012) analysis. The result indicated that the time period concerned affect the trends of the annual average precipitation.

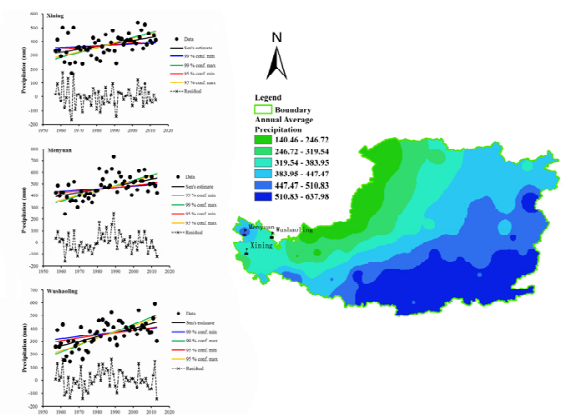

Figure 3. Annual average precipitation trends in the Loess Plateau in Menyuan, Wushaoling, and Xining.

Although the average annual precipitation over the whole Loess Plateau exhibited insignificant trends over the past 57 years (Figure 4), the variation in the annual precipitation did exhibit a close relationship to the seasonal patterns. In our study, precipitation increased in the winter and decreased during the rainy season; moreover, only a few stations in the northwestern part of the plateau exhibited significant increasing trends in annual average precipitation. Combining our results with those of previous studies, and in consideration of global warming, it appears that the seasonal variation of precipitation in the Loess Plateau has declined as a result of the increasing winter precipitation and decreasing precipitation during the summer rainy season. However, both positive and negative trends in annual average precipitation were detected at a few stations in the present study; these changes were probably due to local land use changes, changes in vegetation cover, and other types of human activities. Moreover, the northern high, cold western area of the Loess Plateau appeared to be sensitive to changes in precipitation. This region is 
located near the border of the Tibetan Plateau. The average elevation of the Tibetan Plateau is greater than $4200 \mathrm{~m}$, and the complex topography in this area can affect various regional climate patterns, according to former studies [26]. In particular, the monsoons and the Tibetan Plateau topography can influence regional climatic conditions and precipitation processes in the Yellow River basin. Therefore, the sensitivity of the border area to changes in precipitation, which was observed in this study, was likely due to the combined effects of topography and monsoons.

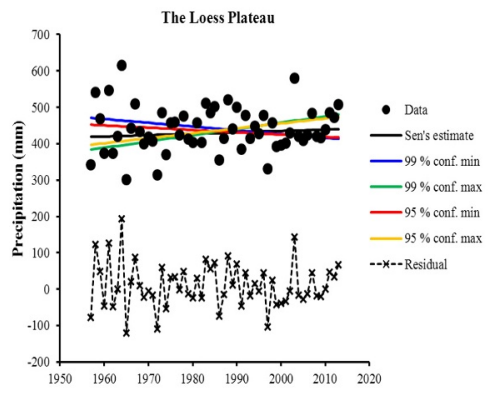

Figure 4. Trends of the annual average precipitation in the Loess Plateau.

\section{Conclusions and implications}

In this study, trends in monthly, seasonal, and annual average rainfall were investigated at 85 meteorological stations in the Loess Plateau for the period 1957-2013. Trends were evaluated for significance using the nonparametric Mann-Kendall test and Sen's slope estimator. On the monthly scale, rainfall between 1957 and 2013 showed positive increasing trends for most of the months. Generally, significant increases in rainfall occurred during the winter in most parts of the Loess Plateau. A limited region representing less than $\sim 20 \%$ of the Loess Plateau showed a significant decreasing trend in monthly rainfall, but this only occurred in April, July, and August. Both positive and negative trends were detected in seasonal and annual daily rainfall data sets. It is noteworthy that all of the stations experienced significant increasing trends in seasonal rainfall during the winter. However, significant positive trends were found at only 12 stations in the spring; nevertheless, nearly $70 \%$ of the stations indicated a tendency toward increasing trends during this time. Similarly, significant positive trends were detected at only six stations in the autumn. The majority of the precipitation trends in the summer were negative. For the annual average rainfall, no significant trends were observed in most parts of the Loess Plateau. Only three significant trends were observed at the $99 \%$ confidence level. The rate of the significant increasing trends in annual rainfall varied from $2.075 \mathrm{~mm} / \mathrm{yr}^{2}$ at the Xining station to $3.427 \mathrm{~mm} / \mathrm{yr}^{2}$ at the Wushaoling station.

Annual average precipitation exhibited a nonsignificant increasing trend $(p>0.05)$ with obvious regional differences over the Loess Plateau. The distribution of the annual average rainfall trends indicated that the significant positive trends mainly occurred in the northwestern part of this region. No significant trends were detected in the other parts of this region. Overall, the changing trends in precipitation over the Loess Plateau showed apparent seasonal and regional patterns. While this study analyzed rainfall trends during the past 57 years from 1957 to 2013, further studies to help identify the root causes and factors that influence the spatial variation of precipitation trends in China would be valuable.

Our findings have important implications for ecological restoration and farming operations in arid and semi-arid regions of the Loess Plateau. Recently research has reported that afforestation leads to risk factors related to environmental degradation, and the greatest carbon sequestration potential is the $400 \sim 500 \mathrm{~mm}$ precipitation isoline. In the Chinese Loess Plateau, how local limited water resources can be used efficiently would be a key question in any afforestation program. Special attention, therefore, should be paid to the selection of suitable tree species according to the spatiotemporal pattern of the natural stochastic rainfall, especially for afforestation in regions with 400 500 mm precipitation. This can not only prevent soil erosion but also promote ecosystem services in the local region. Since different ecological engineering measures have been developed in arid and semiarid ecosystems, higher attention should be paid to improve the composite agroforestry system in this particular case. Namely, the importance of integral agroforestry ecosystem should be well understood and combined with agricultural production management scientifically, particularly in regions with stable rainfall variation. Such agroforestry systems can be also expanded to other similar fragile regions.

\section{Acknowledgment}

The work was funded by the young elite scientist sponsorship program by China Association for Science and Technology (2017 to 2019)

\section{References}

1. Reynolds, JF.; Kemp, PR.; Ogle, K.; Fernández, RJ. Modifying the 'pulse-reserve' paradigm for deserts of North America: precipitation pulses, soil water, and plant responses. Oecologia, 141, 194-210 (2004)

2. Schwinning, S.; Sala, O.; Loik, M.; Ehleringer, J. Thresholds, memory, and seasonality: understanding pulse dynamics in arid/semi-arid ecosystems. Oecologia, 141, 191-193 (2004)

3. Cerdà, A. The influence of aspect and vegetation on seasonal changes in erosion under rainfall simulation on a clay soil in Spain. Canadian Journal of Soil Science 78, 321-330 (1998)

4. Mcauliffe, JR. The interface between precipitation and vegetation-the importance of soils in arid and semiarid environments. Changing precipitation 
regimes \& terrestrial ecosystems: A north american perspective, 9-27 (2003)

5. Reynolds, JF.; Kemp, PR.; Tenhunen, JD. Effects of long-term rainfall variability on evapotranspiration and soil water distribution in the Chihuahuan Desert: a modeling analysis. Plant Ecology 150, 145-159 (2000)

6. Westra, S.; Alexander, LV.; Zwiers, FW. Global increasing trends in annual maximum daily precipitation. Journal of Climate 26, 3904-3918 (2013)

7. Wagesho, N.; Goel, NK.; Jain, MK. Temporal and spatial variability of annual and seasonal rainfall over Ethiopia. Hydrological Sciences Journal 58, 354-373 (2013)

8. Nunes, AN.; Lourenco, L.; Vieira, A.; BentoGoncalves, A. Precipitatin and erosivity in Southern Portugal: Seasonal variability and trends (19502008). Land Deradation \& Development DOI:10.1002/ldr.2265 (2014)

9. Tabari, H.; Talaee, PH. Temporal variability of precipitation over Iran: 1966-2005. Journal of Hydrology 396, 313-320 (2013)

10. Zhang, Q.; Xu, C.; Zhang, Z.; Chen, Y.; Liu, C. Spatial and temporal variability of precipitation over China, 1951-2005. Theoretical and Applied Climatology 95, 53-68 (2009)

11. Luo, Y.; Fu, S.; Liu, J.; Wang, G.; Zhou, G. Trends of precipitation in Beijiang River Basin, Guangdong Province, China. Hydrology Processes 22, 23772386 (2008)

12. Liu, Q, Yang, Z, Cui, B. Spatial and temporal variability of annual precipitation during 1961-2006 in Yellow River Basin, China. Journal of Hydrology 361, 330-338 (2008)

13. Zhao, Q., Liu, S., Deng, L., Dong, S., Yang, J., Wang, C. The effects of dam construction and precipitation variability on hydrologic alteration in the Lancang River Basin of southwest China. Stochastic Environmental Research \& Risk Assessment 26, 993-1011 (2012)

14. Fan, L., Lu, C., Yang, B., Chen, Z. 2012. Long-term trends of precipitation in the North China Plain. Journal of Geographical Sciences 22, 989-1001.

15. Wang, H., Chen, Y., Xun, S., Lai, D., Yan, F., Li, Z. 2013. Changes in daily climate extremes in the arid area of northwestern China. Theoretical and Applied Climatology 112, 15-28.

16. Lv, Y., Fu, B., Feng, X., Zeng, Y., Liu, Y., Chang, R., Sun, G., Wu, B. A policy-driven large scale ecological restoration: quantifying ecosystem services changes in the Loess Plateau of China. PLoS ONE, 7: e31782. (2012)

17. Modarres, R., de Paulo Rodrigues da Silva V. Rainfall trends in arid and semi-arid regions of Iran. Journal of Arid Environments 70, 344-355 (2007)
18. Zhang, X., Yang, F. RClimDex (1.0) User Guide. Climate Research Branch Envrionemnt Canada. Downsview (Ontario, Canada) (2004)

19. Mann, HB. Non-parametric tests against trend. Econometrica, 13, 245-259 (1945)

20. Kendall, MG. Rank correlation methods. London: Charles Griffin, 160 pp. (1975)

21. Sicard, P., Mangin, A., Hebel, P., Malléa, P. Detection and estimation trends linked to air quality and mortality on French Riviera over the 1990-2005 period. Science of Total Environment 408, 1943 1950 (2010)

22. Jaagus, J. Climatic changes in Estonia during the second half of the 20th century in relationship with changes in large-scale atmospheric circulation. Theoretical and Applied Climatology 83, 77-88 (2006)

23. Lu, A. Spatial and temporal precipitation variation on the Loess Plateau in the past half century. Ecology and Environmental Sciences 18, 957-959 (2009)

24. Xin, Z., Yu, X., Li, Q., Lu, X. Spatiotemporal variation in rainfall erovisity on the Chinese Loess Plateau during the period 1956-2008. Regional Environtal Change 11, 149-159 (2011)

25. Wang, Q., Fan, X., Qin, Z., Wang, M. Change trends of temperature and precipitation in the Loess Plateau Region of China, 1961-2010. Global Planetary Change 92, 138-147 (2012)

26. Cui, X., Graf, H., Langmann, B., Chen, W., Huang, R. Climate impacts of anthropogenic land use changes on the Tibetan Plateau. Global Planetary Change 54, 33-56 (2006) 